\title{
PREFÁCIOS E NOTAS DE TRADUTORES BRASILEIROS DOS ANOS 1930 A 1950
}

\section{Cristina Carneiro Rodrigues}

De uma maneira geral, associa-se ética a um comportamento ou ação, a um modo de se relacionar com o outro. Em tradução, diz respeito às relações que se estabelecem entre o tradutor, o texto a ser traduzido, as línguas envolvidas e, para muitos, o leitor. Essas relações não são lineares e estão sempre sujeitas a constante tensão, com forças atuando em diferentes direções. Conforme o tradutor siga mais para uma ou para outra dessas direções, atenda mais a um ou outro fator, produzirá diferentes efeitos, construirá diferentes percepções do outro e, até, de si próprio. Diversos teóricos da tradução têm proposto, ao longo da história, preceitos éticos que visam a regular essas relações que se constroem na transformação que acontece ao se fazer uma tradução. Entre as várias propostas teóricas que indicam um modo de conduzir a prática, uma das mais conhecidas é a de Berman. Em L'épreuve de l'étranger (1984), o autor define a "boa tradução", a tradução ética: é a que não é etnocêntrica, a que não apaga a língua e a cultura estrangeiras. A boa tradução é a "tradução da letra", que abre "no plano da escrita uma certa relação com o Outro" e fecunda "o Próprio pela mediação do estrangeiro"; "é ser abertura, diálogo, mestiçagem, descentralização. Ou a tradução é posta em contato, ou não é nada" (1984: 16). ${ }^{1}$ A "tradução ruim" é a tradução etnocêntrica, que, "geralmente com o pretexto da transmissibilidade, opera uma negação sistemática do estrangeirismo da obra estrangeira" (p. 17). Essas concepções de Berman (1984: 62) são vistas como uma reação contra a tradição francesa das belles infidèles, totalmente adequadas às normas da cultura francesa, que, em lugar de se "abrirem ao influxo das línguas estrangeiras", adaptam-se ao "modo de comunicação das esferas intelectuais e políticas europeias", sem estabelecer diálogo com o estrangeiro. A posição de Berman (1984) aponta para a não aceitação de qualquer adaptação, de qualquer adequação para o público, pois a boa tradução não seria apropriadora nem redutora. $\mathrm{O}$ estrangeiro não deve ser reduzido ao próprio, ao familiar, ao doméstico.

O próprio Berman vai, em certa medida, questionar essas concepções tão conhecidas em Pour une critique des traductions, escrito em 1991, mas publicado

\footnotetext{
${ }^{1}$ As traduções das citações dos livros de Berman (1984 e 1995) foram feitas por mim.
} 
postumamente em 1995. Nessa obra, a radical rejeição ao etnocentrismo cede lugar a outros questionamentos. O objetivo de Berman (1995: 16) é buscar constituir um caminho para se proceder a uma crítica de tradução produtiva, uma crítica que leve em conta quem é o tradutor e promova uma análise rigorosa do projeto que sustenta uma tradução, do horizonte no qual essa tradução se produz e da "posição tradutiva". A concepção do tradutor, sua posição tradutiva, seria uma espécie de compromisso entre como ele percebe sua tarefa e como ele internalizou o discurso histórico, social, literário, ideológico, sobre o traduzir. O projeto seria determinado tanto pela posição tradutiva quanto pelas especificidades da obra a ser traduzida e é o que direciona a prática tradutória, como ela será realizada. Projeto e posição tradutiva inscrevem-se em um horizonte, em um "conjunto de parâmetros linguageiros, literários, culturais e históricos que ‘determinam’ o sentir, o agir e o pensar de um tradutor” (Berman, 1995: 79). Não se trata de um condicionamento causal ou estrutural, mas das concepções sobre o tema, o gênero, a tradição, assim como sobre a tradução, que circulam na comunidade que recebe a tradução.

A análise desses três parâmetros seria articulada, não linear, e envolve uma primeira fase em que se examinam as traduções, e uma segunda fase em que se comparam o original e a tradução, para mensurar "a verdade (e a validade) do projeto", e tem como resultado a avaliação da tradução (Berman, 1995: 83). Para evitar cair "no dogmatismo ou, no mínimo, privilegiar uma certa concepção do traduzir", a avaliação de traduções se fundaria em dois os critérios, de ordem ética e poética (p. 92). Para Berman, "a poeticidade de uma tradução reside em que o tradutor tenha realizado um verdadeiro trabalho textual"; aceita, por sua poeticidade, entre outras obras, "o Lucien de Perrot d'Ablancourt, belle infidèle típica, as Mil e uma noites de Galland, o Poe de Baudelaire”, por serem verdadeiras obras (p. 92). Essas seriam também traduções éticas, porque há um "certo respeito" ao original, dialogam com ele, fazem face a ele. Faria parte dessa ética o tradutor informar o que faz, "jogar um jogo franco", expor suas concepções e suas ações (p. 93). Nesse sentido, o trabalho de Perrot d'Ablancourt é considerado ético por Berman, pois "não dissimula de modo algum suas supressões, seus acréscimos, seus embelezamentos etc.: ele os expõe em seus prefácios e notas, francamente" (p. 94).

Traduções etnocêntricas não são mais rejeitadas por Berman no final de sua vida. O importante passa a ser que o tradutor apresente um "verdadeiro trabalho textual" (Berman, 1995: 92), que se baseie em um projeto tradutivo explícito e que respeite o 
original até certo ponto, assim como os leitores. Como afirma Simon (2001: 25), "sem anunciar com todas as letras, Berman (1995) parece abandonar sua adesão à 'tradução da letra' em favor do que nomeará "projeto de tradução"”.

Projetos e posições tradutivas tanto podem ser verbalizados em prefácios, entrevistas, posfácios, comentários, como podem ser reconstituídos a partir das próprias traduções. Neste trabalho vou concentrar-me na análise de prefácios e comentários escritos por tradutores e especialistas, e publicados em obras sobre o Brasil editadas no período entre 1930 e 1950, buscando inscrevê-los em um horizonte que tanto se constrói no sentir, agir e pensar do tradutor, quanto na tensão entre as forças que atuam sobre ele.

Os prefácios, as notas, o nome do tradutor, o título da obra, as ilustrações, as dedicatórias, são chamados de paratexto por Genette (1982; 1987). Para o autor, pode-se questionar se esses elementos pertencem ou não ao texto, mas eles o envolvem e o apresentam. Nesse sentido, não são situados em termos de limites ou fronteiras estanques, mas como portais que oferecem a possibilidade de passagem para o interior ou para o exterior do livro, assim como constituem-se como um lugar privilegiado para o relacionamento com o público. Apesar de Genette (1987) não tratar especificamente de questões de tradução, considera como alógrafo o prefácio escrito por uma terceira pessoa, categoria que inclui o editor, o tradutor ou um convidado.

Considero que haja, entretanto, uma diferença entre prefácios ou outros comentários escritos pelo editor ou por convidados do autor - esses são legitimados pelo autor, enquanto o tradutor poucas vezes o é. A diferença temporal espacial entre a escritura e a tradução impedem, na maior parte dos casos, que haja a legitimação prévia do tradutor por parte do autor. Mas o editor sempre tem um papel no processo: é ele que autoriza ou não que o tradutor se manifeste.

Muitas das traduções sobre assuntos brasileiros publicadas no período analisado trazem prefácios alógrafos, de tradutores, editores ou especialistas convidados. Em geral, têm a dupla função descrita por Genette (1987): trazem informações sobre o autor, sua obra, o significado do texto na contemporaneidade, assim como recomendam, muitas vezes explicitamente, a leitura da obra. Mas vários prefácios dos tradutores informam também as concepções e estratégias por eles adotadas. Nesse espaço o tradutor verbaliza seu projeto, explicitando uma espécie de quadro de referência em que estabelece sua relação com o texto, com o autor, com as línguas envolvidas, com o leitor e seu comprometimento com essas instâncias. Seria, de acordo com Oliveira (2009: 10) 
"uma ética em primeira pessoa", que se coloca para o sujeito que a propõe, uma atitude que se mostra nas ações do proponente, não uma ética de preceitos a serem seguidos pelo outro, como a ética sugerida por Berman (1984). Essa ética da explicitação é dupla: por um lado, o sujeito tradutor assume um compromisso consigo mesmo, por outro, com o leitor, que sabe o que esperar ao ler a tradução.

Explicitar um projeto, concepções, é algo pouco comum hoje no Brasil. Em geral, os editores são avessos à ideia de que o tradutor se exponha em notas ou que escreva prefácios apresentando seu projeto tradutório, talvez para que o leitor tenha a ilusão de que o texto não foi tocado por ninguém, ou seja, de que estaria tendo contato direto com o autor da obra que lê. No entanto, nas traduções sobre assuntos brasileiros publicadas na primeira metade do século passado pela Companhia Editora Nacional os tradutores tinham grande visibilidade. Muitas das obras traduzidas evidenciam que há mediação - o nome do tradutor não consta apenas da página de rosto, está impresso na própria capa. Um ponto chama a atenção no mapeamento dos títulos traduzidos: se os tradutores não tinham total liberdade para explicitar suas posições em prefácios e notas, pelo menos tinham muita autonomia. Os editores também não pareciam interferir no direcionamento dado às traduções, porque há notas em que os tradutores afirmam atualizar conhecimentos e fornecer novos dados, há tradutores que dizem respeitar a maneira como os coloca o autor. Há tradutores que se declaram fiéis, há outros que nem tanto.

Entre esses, Leonam de Azeredo Pena (1939) é exemplar. No prefácio à primeira edição de Viagem ao Rio Grande do Sul, de Saint-Hilaire, intitulado "Traduttore Traditori", afirma que teve "sempre em mente a velha advertência italiana segundo a qual os tradutores nem sempre são fiéis aos autores” (p. 22). Assim descreve seus procedimentos:

No texto procuramos corrigir os vocábulos toponímicos, porquanto achamos não haver vantagem em mantê-los errados sómente para aparentarmos fidelidade ao original.

Sabido que entre os méritos de um livro como êste salienta-se o seu caráter didático, empenhámo-nos, na medida do possível, em emendar os nomes portuguêses e indígenas. Para exemplificarmos lembraremos que no original (publicado após a morte do Autor) está: Rincão da Bom Monte em vez de Rincão da Boca do Monte. É visível tratar-se de êrro de imprensa, talvez oriundo da caligrafia do Autor, aliada ao desconhecimento de nossa língua por parte do tipógrafo francês. (p. 22)

Corrigir, ou "emendar", nesse caso, relaciona-se diretamente com o respeito ao leitor, com o comprometimento com o "caráter didático" que direciona o projeto de 
Pena. Essa atitude, no entanto, pode ter efeito adverso, na medida que não permite ao leitor avaliar que tipo de equívoco está sendo supostamente corrigido. O tradutor de Viagens aos planaltos do Brasil: 1868, de Richard Francis Burton, o historiador Américo Jacobina Lacombe, adota outro procedimento: grafa corretamente o topônimo ou antropônimo no corpo do texto que traduz, mas acrescenta uma nota informando a ortografia original. ${ }^{2}$ Esse procedimento pode conduzir à formação da imagem de um tradutor arrogante, mas permite ao leitor observar como nossos topônimos ou antropônimos são percebidos pelo estrangeiro.

Os tradutores de relatos de viagens pelo Brasil publicados na época pela Companhia Editora Nacional podem, entretanto, adotar outros procedimentos. Na tradução de Mario Sette da obra Dois anos no Brasil, escrita por François Auguste Biard, lê-se, no verso da página de rosto, que "o tradutor respeitou a grafia do autor em nomes de localidades, tribus indigenas, rios, ilhas e animais das regiões brasileiras percorridas" (p. 2). Postura semelhante tem Alexandre Correia, tradutor de Da medicina brasileira, de Guilherme Piso, arquiatra de Maurício de Nassau que esteve no Brasil no século XVII. Ele afirma conservar a grafia de Piso, "mesmo quando há evidente erro tipográfico" (Correia, 1948: 231). Seu compromisso é com a literalidade, não com o didatismo. Por outro lado, Estevão Pinto, tradutor do antropólogo suíço Alfred Métraux, manifesta comprometimento com o modo de expressão da língua portuguesa. Em seu "Prefácio do tradutor" informa "aportuguesar e simplificar o mais possível" a grafia dos nomes indígenas (Pinto, 1950: 19). Não adota a grafia internacional que inclui letras como $k, w$ e $y$, convenciona empregar iniciais maiúsculas e não flexionar gênero e número. Pinto opta por domesticar o estrangeiro, procedimento que pode ser lido como uma estratégia de resistência, de defesa da língua portuguesa contra a contaminação pelo outro. ${ }^{3}$

São cinco tradutores escrevendo em uma mesma época, para uma mesma editora, explicitando posturas divergentes, causando efeitos diferentes. ${ }^{4}$ Essa

\footnotetext{
${ }^{2}$ Na primeira edição da tradução de Lacombe (Burton, 1941), há apenas uma "nota" de oito linhas em que o tradutor esclarece o sistema de identificação das notas de rodapé e agradece aos revisores. $\mathrm{Na}$ segunda edição (Burton, 1983: 7-15) há um prefácio em que o tradutor discorre sobre a vida e obra do autor, sem informar seu projeto de tradução. Este, no entanto, pode ser identificado nas inúmeras notas de rodapé que pontuam a obra, em ambas as edições.

3 A adoção ou não da grafia internacional é ambivalente e foi discutida por Fiorin e Petter (2008) e Rodrigues (2008).

${ }^{4}$ As traduções de Pena, Lacombe, Sette e Pinto foram publicadas na Coleção Brasiliana, coordenada, na época, por Fernando de Azevedo. Apenas a tradução de Piso teve como editor Affonso de E. Taunay, então diretor do Museu Paulista, que idealizou a publicação.
} 
diversidade de procedimentos sugere a dificuldade de se falar em normas tradutórias nesse período. Mas há situações em que o explicitado nos prefácios se choca com o praticado ou com o experimentado no ato de fazer a tradução, de se relacionar com a obra. Vou abordar, neste texto, dois casos em que o projeto explicitado não condiz exatamente com o realizado.

O primeiro deles é a tradução que Sérgio Milliet faz, em 1942, dos artigos de Max Leclerc publicados no Journal des Débats em 1889 e 1890, reunidos em Cartas do Brasil. No "Prefácio", Milliet (1942) situa o trabalho de Leclerc, por um lado, como ruptura em relação à antiga prática do jornalismo, configurando-se como um dos primeiros conjuntos de reportagens modernas e, por outro lado, como relatórios para uma futura expansão capitalista francesa. De acordo com Milliet, no testemunho sobre os fatos do início dos primeiros anos da Primeira República, Leclerc sublinharia “defeitos graves de nosso temperamento" e "erros lamentáveis de nossa administração", que não poderiam ser ignorados porque esclareceriam o desenrolar dos acontecimentos (p. 8). Apesar de considerar que esses fatos deveriam ser divulgados, Milliet (p. 8) relativiza a confiabilidade do relato do autor, afirmando que "julgamentos apressados, superficiais baseados em observações rápidas ou em informações de terceiros, muitas vezes suspeitíssimos, devem ser postos em quarentena, principalmente no que concerne à psicologia de nosso povo".

Há ambivalência no texto de Milliet: o relato de Leclerc é moderno — rompe com a maneira antiga de redigir reportagens - mas conserva noções colonialistas; é esclarecedor, porém apressado e superficial. E essa tensão persiste por todo o "Prefácio". Milliet (1942: 9) elogia Leclerc, repórter "perspicaz e ativo", um homem que "não perde tempo e sabe olhar. Mas tem os defeitos de suas qualidades, e uma cultura econômica e social [...] assaz rudimentar". Por conta desses defeitos, Leclerc faria certas afirmações sobre o caráter do povo brasileiro que, na opinião de Milliet, não faria se conhecesse um pouco mais de nossa história. Para o tradutor, as observações de Leclerc tanto ajudam a entender o "golpe de Estado ou revolta" e eventos a ela associados, quanto são parciais, por relatarem fatos muito recentes (p. 11).

A tensão evidencia-se em todos esses comentários. Apesar disso, Milliet (1942: 10) afirma que não vai analisar "pormenorizadamente" a obra e deixa ao leitor "o prazer de descobrir as qualidades e defeitos" de Cartas do Brasil de Leclerc. Entende-se, então, que seu projeto é traduzir a obra sem comentários e que quem decidirá se Leclerc é perspicaz e esclarecedor ou suspeito e mal informado sobre nossa história será o leitor. 
No entanto, o livro é pontuado por notas e algumas delas retrabalham a tensão que age no Prefácio. Por exemplo, Leclerc afirma que os brasileiros não têm preconceito de cor, são afáveis e acolhedores, mas há "furor de títulos pomposos" (p. 52). Em nota, Milliet coloca que "a observação é perspicaz, muito embora escapem ao autor as causas sociais desse amor aos títulos" (p. 52); com sua explicação, o tradutor evidencia também que Leclerc erra ao dizer que não há preconceito: de acordo com a explicação de Milliet, ser nobre, no Brasil, "equivalia a ser branco, cristão velho e possível candidato a cargos elevados" (p. 52).

Em outras notas, Milliet defende o brasileiro do olhar estrangeiro. Leclerc observa que, nos últimos anos do Império, o visconde de Ouro Preto distribuiu títulos, mas os novos condes e barões nada fizeram por ele quando proclamada a República. Milliet (1942: 52) retruca afirmando que isso não aconteceu por falta de gratidão, mas "por falta de convicção ideológica". Ante a afirmação de Leclerc de que os paulistas teriam abandonado a "pirataria", renunciando ao ouro e às pedras e dedicando-se à agricultura, Milliet reage: "absurda e superficial essa nota. Que entende o autor por ‘pirataria'?” (p. 63).

Em carta de 19 de janeiro de 1890, Leclerc comenta os desacertos do projeto financeiro delineado por Rui Barbosa, compara-o a um certo Sr. Law e prevê que a reforma não seria implantada. Em longa nota, Milliet explica que esse Sr. Law teria sido um trapaceiro escocês e que não haveria motivo para compará-lo a Rui Barbosa. Mas admite que Leclerc "acertou, ao duvidar de que fosse o projeto financeiro posto em vigor" (p. 112-113).

Milliet usa, ainda, as notas para atualizar ou complementar dados fornecidos por Leclerc. O autor comenta que, apesar do "clima mortífero", com 40 graus à sombra, "obstina-se o brasileiro em viver e se vestir à europeia" (p. 47). Uma nota informa que "nos dias de hoje" tal observação não seria feita, pois os hábitos do carioca haviam mudado (p. 47). Quando Leclerc aponta a falta de precisão dos dados estatísticos, Milliet concorda, afirmando ser "falha que perdura até hoje", apesar dos esforços iniciados em 1920 para minimizar o problema (p. 62). Mas o tradutor também aproveita as notas para corrigir o autor; seu uso da palavra "fluminense" recebe nota informando "em português no texto. Mas o engano é evidente: deve-se corrigir para carioca" (p. 118).

Milliet não se furta a alfinetar o autor no plano político. Leclerc comenta o tratado celebrado entre Brasil e Argentina sobre a região das Missões e suspeita dessa 
"fraternidade americana" (p. 96). Para Milliet, “os imperialistas europeus [...] encaravam com desconfiança a política pan-americanista. Receavam lhes escapassem [...] os nossos mercados em benefício dos Estados Unidos e mesmo dos próprios países latino-americanos" (p. 96). Na opinião do tradutor, o comentário de Leclerc materializa o ponto de vista colonial que tanto impede a criação de indústrias nos países colonizados quanto acredita que ideologias nacionalistas podem ser perigosas aos interesses dos colonialistas (p. 96).

Na penúltima carta, Leclerc discorre sobre sociedade, costumes e instituições brasileiros. Retoma a noção de ausência de preconceito de cor, salienta a apatia, o fatalismo, a paciência e a resignação do povo; Milliet, em nota, sublinha "a superficialidade jornalística de sua [de Leclerc] apressadíssima psicologia coletiva" (p. $154)$.

A leitura de Cartas do Brasil deixa claro que Milliet não permite ao leitor descobrir as qualidades e os defeitos dos relatos de Leclerc - o tradutor se encarrega de apontá-los, especialmente os defeitos. Os princípios previamente anunciados no "Prefácio" não são respeitados ante o que parece a Milliet ser mostra de desconhecimento ou análise superficial do autor. Há, portanto, uma distância entre o explicitado no projeto e o praticado na tradução.

Não há um comprometimento com o manifestado, mas estabelece-se uma espécie de pacto com o leitor, na exteriorização da discordância em relação a certas afirmações de Leclerc. Podemos dizer que Milliet não assume a responsabilidade pelo que afirma? Ou que sua tradução compromete a "veracidade" de seu projeto? Avalio que não, na medida que há, em sua tradução, o movimento ambivalente, a mesma tensão que se delineava no "Prefácio". Milliet é coerente com o implícito em seu texto, ainda que não o seja com o explicitado. Há constante tensão entre as concepções do tradutor e as do autor, entre o explicitado no prefácio e o sentido no ato tradutório. A posição tradutiva de Milliet e o quadro de referência da intelectualidade da época não o conduzem para a relação pacífica anunciada no "Prefácio", e a tensão aflora nas notas de rodapé.

No segundo caso que abordo, há tensão entre o explicitado pelo tradutor, o julgamento do editor do livro e o que o leitor percebe ao ler a tradução. Trata-se da tradução feita por Alexandre Correia, mencionada anteriormente, de Da medicina brasileira, de Guilherme Piso. O livro foi escrito em latim e sua primeira edição foi publicada em Amsterdã em 1648. A edição publicada em 1948 foi projetada por 
Affonso Taunay, em comemoração ao cinquentenário do Museu Paulista, do qual era diretor. ${ }^{5}$ Trata-se de um in-fólio em papel de qualidade que inclui, nessa ordem, o prefácio de Taunay, a tradução do texto, o texto de partida, o escorço bibliográfico de Piso por Taunay, os comentários e notas sobre os quatro livros de Piso, por Alexande Correia, precedidos por "Duas Palavras" do tradutor; a seguir, temos comentários de especialistas, o primeiro sobre medicina; o segundo sobre zoologia; o terceiro sobre botânica médica; o quarto sobre condições climáticas, e o quinto sobre oftalmologia.

O tradutor, no texto intitulado "Duas Palavras", afirma ter demorado meses para fazer a tradução e as notas e acrescenta:

Bem sei que, atirando-me a tão arriscada empresa, fui invadir seara alheia. Entregue a estudos e ocupações de natureza mui diversa, este trabalho só pode ser considerado obra de amador.

Sobre ele não nutrimos a mínima ilusão: deve estar eriçado de erros, numerosos e graves. Erros quanto à fidelidade da tradução e quanto à exatidão das notas.

No tocante à fidelidade, cingi-me o mais literalmente que pude à frase latina de Piso, como o leitor poderá facilmente verificar. E nisso lutei com mais de uma dificuldade, que procurei resolver como me foi possível. (p. 231)

Ora, é desconcertante a maneira como o tradutor expõe as difíceis relações que estabeleceu com o texto de Piso, com sua linguagem e até com sua matéria, pois ele também diz que "só um naturalista e médico versado na história da Medicina poderia deslindar com proficiência mais de uma dificuldade" (p. 231) - e ele se declara leigo no assunto. No entanto, no "Prefácio", Taunay afirma ter confiado a tradução ao Prof. Alexandre Correia por ser "figura na primeira plana dos latinistas e helenistas nossos contemporâneos" (p. v), informa que o próprio tradutor exigiu que a publicação incluísse o texto latino de Piso, para que o leitor pudesse estabelecer a comparação entre os textos e acrescenta: "traduzindo o original pisoniano entusiasmou-se o Prof. Correia. Achou-o interessantísimo e propôs-me lhe confiasse a redação de comentários a ele atinente" (p. v). A tensão aqui se estabelece entre a proposta do tradutor ao editor, o entusiasmo a ele manifestado, e a maneira como apresenta o resultado — um trabalho “eriçado de erros". Ora, a tradução tem 137 páginas e as notas do tradutor são 416, em 96 páginas. Um tradutor que dedica meses ao trabalho e escreve mais de 400 notas,

\footnotetext{
5 No "Prefácio" assinado em 02 dez. de 1945, o historiador Taunay (1948: vii) explica as razões pelas quais o livro não havia sido lançado em 1945, ano do cinquentenário do Museu: alta dos preços de publicação, carência de papel adequado, "congestão dos serviços das oficinas gráficas de São Paulo". Apenas após entendimentos entre Taunay e Octales Marcondes Ferreira, da Companhia Editora Nacional, "a custosa publicação" foi impressa.
} 
algumas de mais de uma página in-fólio, com textos em grego, alemão, latim e referências a vários autores e dicionários, não pode crer que esteja errado. No entanto, ele ainda indica sua deficiência em relação à língua:

Uma coisa é um trecho de latim clássico e literário, ou de latim medieval e escolástico, despido de elegância mas claro e rigoroso na sua terminologia, e outra passar para linguagem esse latim moderno e científico, digamos assim, como o de Piso. É uma língua muitas vezes bárbara, comparada com a de César ou Cícero, e forçada a explicar noções científicas ignoradas dos romanos. (p. 231)

Mesmo o laborioso trabalho feito nos comentários é depreciado:

No atinente às notas, confio numa indulgência ainda maior.

Muitas fontes de nenhum modo pude consultar. Onde, na pobreza do nosso meio em matéria de bibliotecas especializadas, iria eu achar um Avicena, um Serapião, um Rases, um Dioscórides, um Galeno, um Monardes, um Zacuto Lusitano e ainda outros, necessários contudo a ilustrar vários lugares de Piso ou para verificar a exactidão das suas citações?...

Já me considerei muito feliz em ter à mão um Hipócrates e uma boa edição inglêsa de Celso, com o texto latino. (p. 231)

Em várias notas remete à segunda edição do livro de Piso, afirmando ser texto esclarecedor. Sua pesquisa é minuciosa, até surpreendente para a época, apesar de reclamar da pobreza de nossas bibliotecas. Para dar uma noção do trabalho de Correia, comento uma nota aposta a um trecho em que se menciona que os "porcos anfíbios" são "chamados capiveres pelos portugueses" (p. 11). Nessa nota, o tradutor informa quais palavras outros 15 autores usaram para designar a capivara, com os números das páginas em que o termo é encontrado. Mas não se limita a isso, explica como esses outros autores denominaram a anta, a paca, o tatu, o lagarto e ainda cita trechos das descrições dos animais feitas por vários naturalistas.

O discurso do prefácio de Correia diverge do que afirma Taunay e do cuidadoso trabalho que faz. Configura-se como o tipo de prefácio de autocrítica preventiva descrito por Genette (1987: 193) como um recurso da eloquência clássica: "face à importância de seu tema, às vezes exagerada além das medidas, o orador assume sua incapacidade de tratá-lo com todo o talento necessário". Seria um meio de se prevenir das críticas ou de neutralizá-las, assim como de conseguir a adesão do leitor. Note-se, entretanto, que dos cinco comentaristas apenas dois fazem o total de três observações que remetem à tradução. Duas delas interpretam, à luz dos conhecimentos contemporâneos, expressões obscuras usadas por Correia, remetendo ao fato de o 
tradutor ter utilizado termos específicos da época de Piso, que remontam às doutrinas hipocráticas. Essas observações apenas confirmam que o tradutor foi coerente com seu projeto de cingir-se o mais literalmente que pode à frase latina de Piso. ${ }^{6}$ Apenas a terceira observação, feita pelo segundo comentarista, pode sugerir uma escolha pouco feliz do tradutor; este intitula um capítulo como "Das doenças dos olhos" e o comentarista pondera que Piso preferiu a frase "De ocularum vitiis", explicando que vitium é palavra "genérica, corresponde à expressão distúrbio, no sentido de estado mórbido, e não rigorosamente doença" (p. 348). Como o comentário não chega a mencionar "erro", mas apenas aponta certa falta de rigor, e como os demais comentaristas não notam equívocos, a autocrítica preventiva de Correia parece totalmente desnecessária.

No entanto, o efeito que causa é o de um tradutor abatido sob o peso do original. É a imagem do tradutor melancólico como descrito por Lages (1992: 92), que "dirige acusações contra si mesmo", que "não cessa de se auto-reprovar, dirigir todo tipo de acusação à própria pessoa", que acha que não conseguiu o suficiente, por mais que tenha se empenhado no trabalho. Mas que não deixa de mencionar a opinião de Taunay sobre a importância de seu trabalho, ainda que a minimize, afirmando que ela seria ilusória:

Se pois meti ombros à temerária empresa, foi somente para ocorrer aos desejos do meu prezado Amigo e ilustre historiador, Affonso de E. Taunay que, iludindo-se com os meus fracos méritos, pensou pudesse ser de utilidade para a História Pátria a minha colaboração. (Correia, 1948: 231)

Há evidente tensão entre os méritos atribuídos por Taunay ao tradutor Alexandre Correia e sua autoapreciação - ou autodepreciação. Há também descompasso entre o que o tradutor afirma e o que o leitor encontra, ao examinar a tradução: como diria Berman (1995), trata-se de um verdadeiro trabalho textual. Assim, como no caso do tradutor Millet, há um conflito entre o que explicita o tradutor e o que ele faz. Podemos dizer que Correia não assume a responsabilidade pelo que afirma e compromete a veracidade de seu projeto? Creio que não, mas no caso de Correia, diferentemente do ocorrido com Milliet, a tensão não se resolve no embate de palavras com o autor.

\footnotetext{
${ }^{6}$ O primeiro comentarista afirma que "algumas expressões empregadas carecem de interpretação", e explica o que significava, no século XVII, “digestão", "membros internos e externos", "gordura” (p. 347). O último comentarista observa que "a obra é escrita em latim, língua adotada nas publicações científicas da época, e a tradução apresenta dificuldades. Escrita com elegância, o trecho literalmente traduzido é pouco compreensível", e explica a expressão de difícil entendimento (p. 434).
} 
Correia, passivamente, apenas manifesta sua inferioridade ante o autor e a língua por ele utilizada.

Com esses dois exemplos quero evidenciar que a análise proposta por Berman - especialmente do projeto e do horizonte no qual se produz uma tradução - não pode passar apenas pelo exame do que é explicitado; deve abordar também o que não é francamente exposto, mas construído nos prefácios, notas e textos. Pensar em uma avaliação no plano da ética que envolva a análise do projeto que sustenta a produção da tradução é refletir sobre a responsabilidade do tradutor, mas é também pensar nesse projeto como construído em permanente tensão - como estão as forças que atuam sobre o sujeito tradutor. Tanto Milliet como Correia evidenciam o conflito, mas respondem a ele de diferentes maneiras. Enquanto Correia se abate sob o peso do texto de partida, Milliet reage contra o olhar estrangeiro. Analisar traduções fundamentandose em uma ética da explicitação não se limita a checar a "veracidade" do projeto, pois o pensar, o agir, o sentir do sujeito tradutor envolvem uma série de outras questões, como as que apontei, que não necessariamente resultam em uma tradução que pacificamente espelha o projeto. Pelo contrário, analisar os paratextos em que se constroem os projetos e os horizontes tradutivos envolve examinar todas as tensões e pressões a que está submetido o sujeito tradutor.

\section{Referências bibliográficas}

BERMAN, Antoine (1984) L'épreuve de l'étranger: culture et traduction dans l'Alemagne romantique. Paris: Gallimard. (1995) Pour une critique des traductions: John Donne. Paris: Gallimard.

BIARD, François Auguste (1945) Dois anos no Brasil. São Paulo: Ed. Nacional.

BURTON, Richard Francis (1941) Viagens aos planaltos do Brasil: 1868. Trad. de Américo Jacobina Lacombe. São Paulo: Ed. Nacional.

(1983) Viagens aos planaltos do Brasil. 2. ed. Trad. de Américo Jacobina Lacombe. São Paulo: Ed. Nacional.

CORREIA, Alexandre (1948) "Duas palavras". Guilherme Piso. Da medicina brasileira [História Natural do Brasil ilustrada]. Trad. de Alexandre Correia. São Paulo: Ed. Nacional.

FIORIN, José Luiz \& PETTER, Margarida (2008) "Prefácio". $\&$ Paulo: Contexto. (orgs.) África no Brasil: a formação da língua portuguesa. São

GENETTE, Gérard (1982) Palimpsestes: la littérature au second degré. Paris: Seuil. (1987) Seuils. Paris: Seuil.

LAGES, Susana Kampf (1992) "O tradutor e a melancolia". Trabalhos em Linguística Aplicada, Campinas 19, 91-98.

LECLERC, Max (1942) Cartas do Brasil. Tradução, prefácio e notas de Sérgio Milliet. São Paulo: Ed. Nacional. 
MILLIET, Sérgio (1942) "Prefácio". Max Leclerc. Cartas do Brasil. São Paulo: Ed. Nacional.

OLIVEIRA, Paulo (2009) "Conhecimento e valor: a Ética em primeira pessoa de Wittgenstein e suas implicações para os Estudos da Tradução". Tradução em Revista 7 (no prelo).

PENA, Leonam de Azeredo (1939) “Traduttore Traditori”. Auguste Saint-Hilaire. Viagem ao Rio Grande do Sul (1820-21). São Paulo: Ed. Nacional.

PINTO, Estevão (1950) "Prefácio do tradutor". MÉTRAUX, Alfred. A religião dos Tupinambás e suas relações com as demais tribus tupi-guaranis. São Paulo: Editora Nacional.

PISO, Guilherme (1948) Da medicina brasileira [História Natural do Brasil ilustrada]. Trad. de Alexandre Correia. São Paulo: Ed. Nacional.

RODRIGUES, Cristina Carneiro (2008) "A ética da apropriação". Tradução \& Comunicação 17, 21-28.

SIMON, Sherry (2001) "Antoine Berman ou l'absolu critique". TTR: Traduction, Terminologie, Rédaction 14 (2), 19-29.

TAUNAY, Affonso (1948) "Prefácio". Guilherme Piso. Da medicina brasileira [História Natural do Brasil ilustrada]. Trad. de Alexandre Correia. São Paulo: Ed. Nacional. 